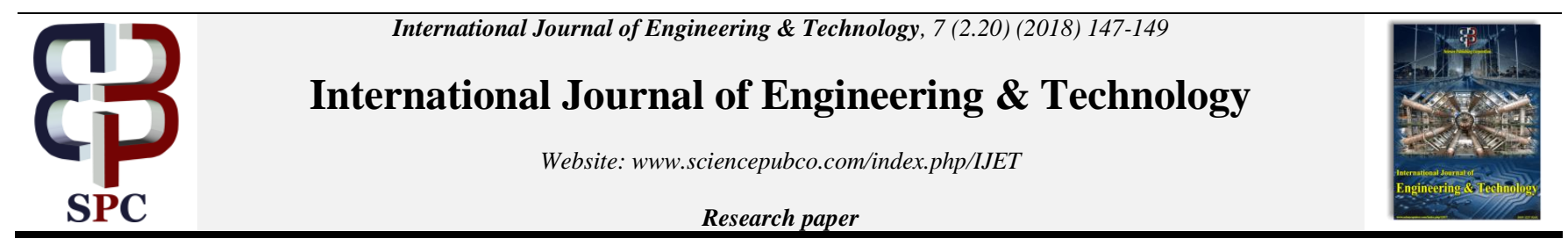

\title{
Unmanned fuel system using RFID tools
}

\author{
V. Usha ${ }^{1}{ }^{*}$, C. Saranya Jothi ${ }^{1}$, G. Yuvaraj ${ }^{1}$, Thanjaivadivel $M^{1}$ \\ ${ }^{I}$ Assistant Professor Department of Computer Science and Engineering, School of Computing Vel Tech Rangarajan Dr. Sagunthala \\ $R \& D$ Institute of Science and Technology, Avadi, Chennai-62, TamilNadu \\ *Corresponding author E-mail: husha88@gmail.com
}

\begin{abstract}
In current days, fuel stations are worked physically. These fuel pumps are tedious and require more labor. To put fuel stations in removed zone it expensive to give brilliant office to the purchasers all these issue are dealt with by the utilization of unmanned oil pump which requires less time to work and it is viable and can be introduced anyplace the client self-going to benefit the administrations the installment is finished by electron-ic clearing framework. The straightforward and legitimate utilization of microcontroller and GSM innovation gives an aggregate security and atomization in the conveyance of fuel. It has simple worked cell phone framework and client interface (GUI). It interfaces with rapid fuel gadget, which is advantageous for the purchaser to work. In our framework the watchword will be given to the client and client needs to enter this secret key on the LCD gave by the fuel station which will enable the oil to organization to make confirmation for the client additionally the dispersion of the fuel isn't conceivable until the point when it gets confirmed by the database. To put it plainly, we give a protected framework to fuel dissemination. The headway of this task can help industry monetarily.
\end{abstract}

Keywords: GSM; LCD; GUI; Atomization; Client.

\section{Introduction}

Today all petroleum pumps have a controlling unit to play out the errands like dealing with the electrical pump, drive the show, measure the stream and as needs be kill the electrical pump. Yet at the same time, a man is required to gather the cash. This task goes for planning a framework to dispense with this human connection as that there is no need of laborers to fill the petroleum. In this framework, all drivers have a brilliant card. There are different highlights of our undertaking. It can offer number of preferences to the client. The expansion in the quantity of vehicles in India as of late has prompted the blockages and automobile overloads in all urban communities of India. The apportioning of the fuel to this tremendous number of vehicles at the fuel stations has caused numerous difficulties in India. The vehicle driver needs to pay for fuel with greenbacks and may need to pay more than the measure of administered fuel because of the absence of little cash change accessible with station administrator.

RFID Based Automated Petrol Pump is to decrease human work and build up an auto-guided component and to actualize the errand consecutively by utilizing RFID innovation. These frameworks are exceedingly solid and less tedious gadgets. The parts utilized as a part of this venture are 8051 Micro-controller, RFID labels, Power supply, a LCD show, a Motor driver and a RFID peruser. Oil based goods are one of the significant and uncommon manifestations of the nature. The correct utilize and dispersion is a critical undertaking to survive these items [1]. A fuel station is an office which offers fuel and ointments by means of fuel containers or generally called browser which themselves are utilized to pump gas, Diesel, lamp fuel, and so on into vehicles and to compute the money related cost of the item along these lines administered [3]. Endeavors occupied with urban and rural open transport and in addition other transport undertakings huge fuel customers require control of fuel conveyance to anticipate or if nothing else limit the abuse of the fuel [2]. The crisis of radio recurrence innovation has changed the customary techniques for information accumulation. Contrasted with the customary scanner tag, attractive card and IC cards, RFID labels have the highlights of non-contact, perusing speed, no wear, long life, easy to understand and the security work [7]. The utilization of RFID for vehicle distinguishing proof, toll gathering, and movement administration have just been tried different things with broadly [8]. This paper proposes the execution of RFID innovation in controlling fuel administering for an Indian urban areas.

\section{Literature survey}

Today the framework which is in wide utilize includes the training took after from numerous years. This includes the people which they fill the petroleum. This framework includes numerous inconveniences which may prompt spillage of oil at different occurrences while the filling the oil. This occurs because of simple altering of fixed oil and more human obstruction. What's more, the principle impediment of the present framework is still in the petroleum bunks they require two people one for filling the oil and another to gather the money. To maintain a strategic distance from this am actualizing unmanned oil bunk framework without the utilization of labor just relying on the machine control this procedure is utilized. Still persons are required. To collect the CASH and to fill the Petrol in the vehicle tanks.

\subsection{Physical control}

In this, Manual Operation finishes the control and mechanization. Downside: Human Errors in this manner influences the nature of finished result. Hard Wired Logic Control. In this, Contractors and 
Relays together with clock and counters were utilized as a part of accomplishing wanted level of Automation. Massive and complex wiring, Involves parcel of adjust to execute changes in charge rationale, Work can be begun just when it is completely characterized which prompts longer venture time.

\subsection{Electronics control with logic gates}

In this, Contractors and Relays together with tillers and counters were supplanted with rationale entryways hardware clock in charge circuit. Preferred standpoint: Reduced extra necessity, vitality sparing, less support and consequently more prominent unwavering quality.

Downside: Implementation of changes in the control rationale and lessening venture lead-time was impractical.

\subsection{Programmable logic controls}

Unmanned Petrol Bunk System utilizes Smart card known as 'PETRO CARD'. That is an RFID card .Petro card is given client confirmation code and it can be energized at revive focuses at the season of utilization the client swaps the petro card and after that the shrewd card peruser faculties the sum in the card and construct up with respect to the data entered by the client the gadget works to convey the oil, naturally the use sum is deducted from the clients account. Here we exhibited a LCD show to introduce the data with respect to utilization of credits in the clients account. At the Petrol Pump, the driver swaps the card and the brilliant card peruser peruses the sum in the card and will show it on the LCD. The driver at that point enters the amount of petroleum that must be filled utilizing a keypad. The comparing sum is figured and deducted from his petro card. The electrical pump is then turned $\mathrm{ON}$ as per the entered sum, fills the tank and consequently kills. The reason for this undertaking is to give a security based getting to framework for filling petroleum at the oil bunks to maintain a strategic distance from the danger of conveying cash without fail. And furthermore gives the element of paid ahead of time revive. A keen card, chip card or incorporated circuit card (ICC) is characterized as any pocket-sized card with implanted coordinated circuits which can process data. This suggests it can get input which is prepared by method for the ICC applications and conveyed as a yield. In this task, we are utilizing a contact brilliant card where the data inside the card is spoken with the card peruser by embeddings card into the card peruser. The card peruser in this undertaking utilized is a SR-90 SDK of $1 \mathrm{~KB}$ memory estimate.

As a matter of first importance the oil pump with our innovation can be conceivable to work all the time without help of labor, In this task there will be a brought together server having the database of the client like Customer Name, Card No, After paying the money the adjust can be expanded and relying on the utilization of the card for buy of oil the adjust will be deducted.

The expansion in the quantity of vehicles in India as of late has prompted the blockages and automobile overloads in all urban communities of India. The apportioning of the fuel to this tremendous number of vehicles at the fuel stations has caused numerous difficulties in India. The vehicle driver needs to pay for fuel with greenbacks and may need to pay more than the measure of administered fuel because of the absence of little cash change accessible with station administrator. RFID Based Automated Petrol Pump is to decrease human work and build up an auto-guided component and to actualize the errand consecutively by utilizing RFID innovation. These frameworks are exceedingly solid and less tedious gadgets. The parts utilized as a part of this venture are $8051 \mathrm{Mi}-$ crocontroller, RFID labels, Power supply, a LCD show, a Motor driver and a RFID peruser.

Oil based goods are one of the significant and uncommon manifestations of the nature. The correct utilize and dispersion is a critical undertaking to survive these items. A fuel station is an office which offers fuel and ointments by means of fuel containers or generally called browsers which themselves are utilized to pump gas, Diesel, lamp fuel, and so on into vehicles and to com- pute the money related cost of the item along these lines administered. Endeavors occupied with urban and rural open transport and in addition other transport undertakings huge fuel customers require control of fuel conveyance to anticipate or if nothing else limit the abuse of the fuel. The crisis of radio recurrence innovation has changed the customary techniques for information accumulation. Contrasted with the $\mathrm{n}$ customary scanner tag, attractive card and IC cards, RFID labels have the highlights of non-contact, perusing speed, no wear, long life, easy to understand and the security work [5]. The utilization of RFID for vehicle distinguishing proof, toll gathering, and movement administration have just been tried different things with broadly [8]. This paper proposes the execution of RFID innovation in controlling fuel administering for an Indian urban areas Clients utilize RFID card: Petro Card with RFID labels including client check codes. These cards can be energized at the revive focuses. At the point when a client swipes the card through the RFID peruser, [9] it detects the sum entered by the client and conveys fuel to the vehicle.

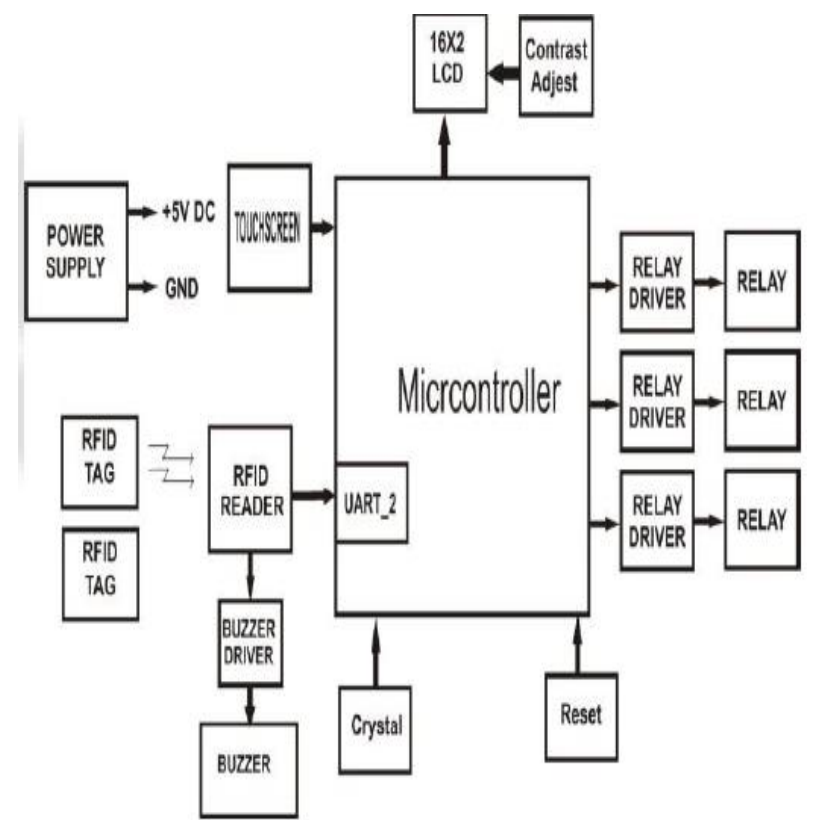

Fig 1:.Block Diagram of the Proposed System.

In this manner, the sum will be deducted naturally from the client card and the LCD show demonstrates the sum and subtle elements of the user. The microcontroller stores a few cards points of interest and thinks about the information given by the [4] RFID peruser. At the point when both these subtle elements coordinate, it sends the control signs to the hand-off with the end goal that the engine works to pump oil.

The framework proposed states three straightforward employments of [6] RFID brilliant cards. Among these two cards are known and the rest is obscure. At the point when the client comes to fill the fuel at the station, right off the bat he will swipe the card. In the event that the card is approved, RFID card peruser will acknowledge the card. At that point, it will request the stick number. In the event that he entered stick, number by the client is right then it will request the sum for the oil to be apportioned. In such a way framework works.

In the event that the client swipes with unapproved card, at that point the peruser will show the mistake message as the card is unapproved. [10] In such a way the framework is secured. This framework does not require any superior smaller scale controller, for example, ARM arrangement. It is some utilizing ease smallscale controller, which by implication decreases the cost of the aggregate framework. Flowchart description in our framework to start with, we embed Based Card. It is utilized to peruse the brilliant card, which incorporates the glorious flag. In the wake of embeddings based card, the framework asks the secret word then we enter classified watchword, Then framework ask the quantity. After that enter amount and get oil. 


\subsection{Befits of the projected system}

Labor is decreased on account of mechanized self-benefit. Due to utilization of RFID framework burglary of the fuel is maintained a strategic distance from. The time is spared. Low power utilization. Accuracy in the measure of petroleum administered. Highly touchy.

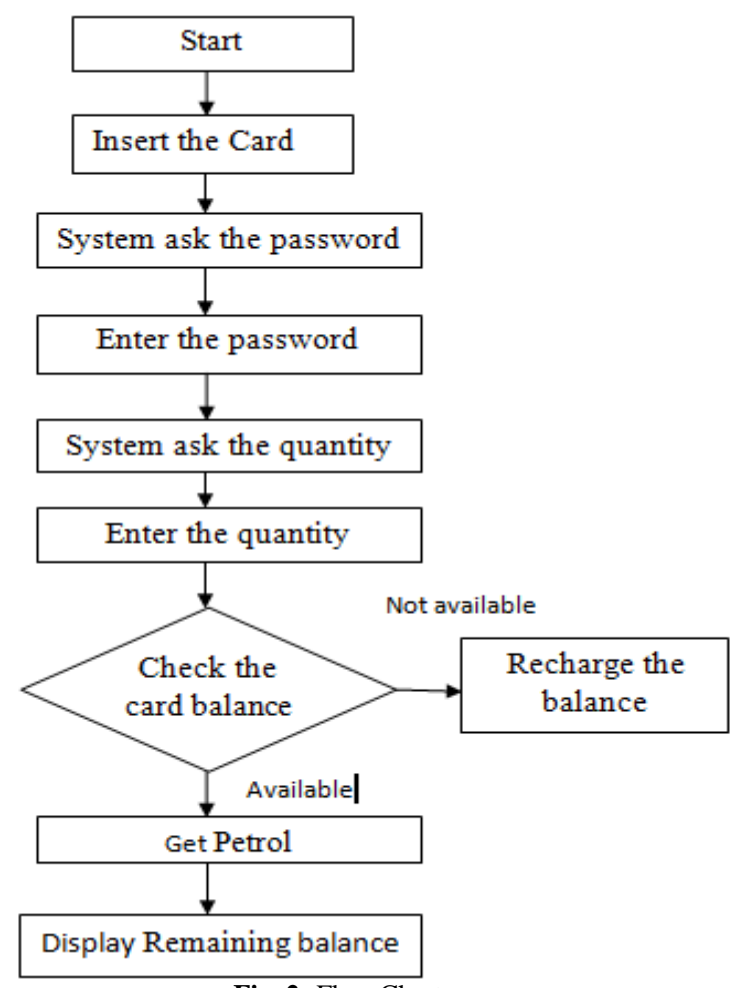

Fig. 2: Flow Chart.

\section{Conclusion}

This task is implied for security frameworks whose entrance is just for regarded experts. Utilizing a microcontroller the petroleum pump is outfitted with a savvy card peruser/compose. At the Petrol Pump, the driver swaps the card and the shrewd card peruse the sum in the card and will show it on the LCD. The driver at that point enters the amount of petroleum that must be filled utilizing a keypad. The comparing sum is ascertained and deducted from his petro card. The electrical pump is then turned $\mathrm{ON}$ as indicated by the entered sum, fills the tank and naturally kills. Our electronic framework executed of course. We could execute every one of the capacities determined in our proposition. The greatest obstacle we needed to overcome with this venture was interfacing the smallscale controller with the equipment parts. We feel that this electronic framework is extremely attractive in light of the fact that it is anything but difficult to utilize, similarly modest because of low power utilization, and profoundly solid. By utilizing this task, one can plan a secured framework. For filling petroleum to vehicles at the oil, bunks utilizing Smart Card based Accessing System

\section{References}

[1] O. O. Edward, "A research using remote monitoring technology for pump output monitoring in distributed fuel station in Nigeria," International journal of Advances in Engineering \& Technology, vol. 6, no. 6, pp. 2408-2415, January 2014.

[2] Z. Cekerevac, S. Matic, D. Duric and D. Celebic, "Fuel dispenser control system as the technical solution for preventing nonauthorized fuelling," in 11th International Scientific Conference devoted to Crises Situations Solution in Specific Environment, Zilina, 2006.

[3] M. A. Kulkarni and S. S. Taware, "Embedded security system using RFID \& GSM,'International journal of computer Technology and Electronics Engineering (IJCTEE), vol. 2, no. 1, pp. 164-168, 2011.

[4] Patil Aishwarya M., Phuke sayali J., Tapase snehal B., "College access and student attendance using 'RFID' technology.

[5] A.H. Jadhav, R. S. Pawar, P. M. Pathare, K. D. Pawar and P. Patil, "Multi-Automized fuel pump with user security, "International Journal of Scientific \& Technology Research, vol. 3, no. 5, May 2014.

[6] P. Jaska, D. B. A. Johnson, J. Nalla, N. V. K. Reddy and R. Tadisina, "Improved customer service using RFID technology, "Review of business Information Systems, vol. 14, no. 3, 2010.

[7] C. H. Li, "Automatic vehicle identification (AVI) system based on RFID," in IEEE International Conference on Anti-Counterfeiting Security and Identification in Communication (ASID), Aug, 2010.

[8] N. Jeevagan, P. Santosh, R. Berlia and S. Kandoi, "RFID based vehicle identification during collisions," in IEEE Global Humanitarian.

[9] Usha V ,Saranya, J.C.,Ravikumar, S.”Effective manless vehicle charging system with RFID" International Journal of Civil Engineering and Technology Volume 8, Issue 9, September 2017, Pages 733-740

[10] V Usha, N Rajkumar, Dr M. Shyamala Devi, C Saranya Jothi"GSM based door open and closing system"International Journal of Engineering and Technology (UAE),vol 7,No 2.4(2018):issue 4,page:97-100. 